\title{
Agronomic Assessment of Upland Rice Varieties under Unpredictable Rains in the Semi-Arid Conditions of South-Western Agro-Ecological Zone of Uganda
}

\section{Robert Muzira ${ }^{1}$, Laban Turyagyenda ${ }^{2}$, Peace Kankwatsa ${ }^{1}$, Hellen Mutenyo ${ }^{1}$, Steven Natuha ${ }^{1}$, Maggiore Kyomugisha ${ }^{1}$}

\author{
${ }^{1}$ National Agricultural Research Organization, Mbarara-ZARDI, Uganda \\ ${ }^{2}$ National Agricultural Research Organization, Ngeta-ZARDI, Uganda \\ Email: ^nrmuzira@yahoo.com, labanturyagyenda@gmail.com, kankwatsap@gmail.com, mutenyoh@gmail.com, \\ natuhasteven@yahoo.com, maggiore2011@gmail.com
}

How to cite this paper: Muzira, R., Turyagyenda, L., Kankwatsa, P., Mutenyo, H., Natuha, S. and Kyomugisha, M. (2020) Agronomic Assessment of Upland Rice Varieties under Unpredictable Rains in the SemiArid Conditions of South-Western Agro-Ecological Zone of Uganda. Open Access Library Journal, 7: e5988.

https://doi.org/10.4236/oalib.1105988

Received: December 9, 2020

Accepted: December 26, 2020

Published: December 29, 2020

Copyright $\odot 2020$ by author(s) and Open Access Library Inc.

This work is licensed under the Creative Commons Attribution International License (CC BY 4.0).

http://creativecommons.org/licenses/by/4.0/

\begin{abstract}
This paper examined agronomic performance of three upland New RICE for Africa (NERICA) varieties promoted by the Government of Uganda in its efforts to improve household food and income security among smallholder farmers. Three rain-fed experimental trials were conducted on station at Mbarara Zonal Agricultural Research and Development Institute (MBAZARDI), with semi-arid climate conditions typical of more than $50 \%$ of the South-Western Agro-Ecological Zone (SWAEZ) of Uganda. The experimental trials were established in the long rain seasons that often occur in September-December period. But results for only one successful long rain seasonal trial of 2010 are presented in this paper. Successful experimental trial for upland NERICA had an average precipitation of $130 \mathrm{~mm}$ that was well distributed especially from booting stage, which is the most sensitive growth stage for upland NERICA. During the growth period, NERICA 1 and NERICA 4 were significantly taller $(\mathrm{p}<0.05)$ than NERICA 10. NERICA 4 had the highest yields: two-folds that of NERICA 1, but four-folds lower than that obtained in Namulonge Crops Resource Research Institute (NACRRI), the breeder station for NERICA in Uganda. Grain yields of NERICA 4 were also below the national average of rice productivity estimated at $2.5 \mathrm{t} \cdot \mathrm{ha}^{-1}$. Although, NERICA 4 ranked top in terms of grain yields among the tested upland NERICA varieties and therefore, most possible candidate for smallholder rice farmers in the humid parts of the SWAEZ, it called for more breeding for upland NERICA varieties with traits that could increase their tolerance to low soil moisture most prevalent
\end{abstract}


in the SWAEZ.

\section{Subject Areas}

Agricultural Science

\section{Keywords}

NERICA, Drought, Grain Yields, Traits, Physical Characteristics

\section{Introduction}

Rice as a crop was introduced in Uganda as early as 1904 by Indian community, who were Asian traders [1]. At that time, rice as food was not popular in the country, more especially with Ugandan citizens, until late 1940s [2]. It was largely imported from Asia, and rice cuisines were majorly considered exotic and expensive: only affordable by wealth communities such as Indians, Europeans, and few affluent Ugandan citizens. After 1940s, few Ugandan farmers especially in eastern parts of the country started growing paddy rice on a subsistence scale.

In 1950s, after World War II, Ugandan government promoted paddy rice production as a need to feed its increasing population and supplement foods used in schools and hospitals [2]. During that period, paddy rice was majorly grown in large wetlands: Doho, Olweny, Omunyal, and Kibimba located in Butalenja, Lira, Soroti and Bugiri districts, respectively. This made paddy rice production popular in the eastern and northern parts of the country. Nonetheless, in 1966, a large scale paddy rice irrigation scheme was introduced in Kibimba wetlands through partnership between the government of Uganda and the People's Republic of China. The main objective of the partnership was to boost in-country food production that would eventually reduce upon food imports, thereby saving the country's foreign currencies. The irrigation scheme was also supported because it was an opportunity for Uganda to diversify export earnings especially on non-traditional export crops such as paddy rice [2].

Paddy rice being promoted by the Ugandan Government, led to its uptake by smallholder farmers, majorly in the eastern and northern parts of the country, as there was an increased need for enhanced household food and income security. Nonetheless, by 2000, large scale production of paddy rice escalated wetlands degradation, leading to reduction of wetland biodiversity, products and services [3]. This caused conflicts between rice cultivators and other wetland users such as cattle keepers, fishermen, and those involved in crafts and ecotourism.

In recent decades, Ugandan government has encouraged farmers to switch from paddy to upland rice production in order to save wetland ecosystems and their benefits. It also emphasized farmers outside the traditional rice growing districts such as those located in the South-Western Agro-Ecological Zone 
(SWAEZ) of Uganda to embrace upland rice production in an effort to alleviate household food insecurity and poverty among rural communities. Hence, to respond to the government's call, National Agricultural Research Organization (NARO) with support from Japan International Cooperation Agency (JICA), evaluated agronomic and economic yield of three New Rice for Africa (NERICA) varieties promoted in the existing semi-arid conditions of the SWAEZ. Adaptation of NERICA varieties to the semi-arid conditions of SWAEZ would bring an additional crop in the existing banana farming systems, giving farmers alternative options for improving household food and income security. Results for only one successful trial are presented in this paper. Other two on-station trials failed due to insufficient soil moisture at the booting stage, which is considered, one of the most sensitive physiological stages of rice growth. Lack of rains at that period resulted in poor grain filling, even with increased soil moisture after the booting stage.

\section{Origins and Identification of NERICA Varieties}

The term NERICA stands for "New Rice for Africa" with over 3000 siblings having wide variation of agro-physiological expressions [4]. NERICA is derived from successful crossing of African rice (Oryza glaberrima Steud.) and the Asian rice (Oryza sativa L.) [5]. NERICA combines good traits of high grain yields of Asian rice and tolerance to harsh environment associated with African rice. NERICA rice is produced through conventional crossbreeding (Table 1) and is made to adapt to the rain-fed upland ecology in sub-Saharan Africa (SSA) associated with low inputs in terms of irrigation, fertilizers and pesticides. Nonetheless, NERICA responds better than the local rice varieties under high input production systems [4]. The adoption of new NERICA varieties in SSA is far more rapid compared to other crop technologies due to its high grain yield potential. Hence, NERICA seeds offer hope to millions of poor population in SSA, spending most of their meager income on rice [5].

\section{Methodology: Materials and Methods}

\subsection{Study Site}

The experiment was conducted on station at Mbarara Zonal Agricultural Research and Development Institute (MBAZARDI), located at $0.6026^{\circ} \mathrm{S}, 30.6106^{\circ} \mathrm{E}$ in the SWAEZ of Uganda (Figure 1), characterized with the semi-arid conditions.

Table 1. NERICA pedigree names of the rice varieties used in the experiment.

\begin{tabular}{ccc}
\hline NERICA & LINE CODE & PARENTS \\
\hline NERICA 1 & WAB 450-IBP-38-HB & WAB 56-104/CG 14//2*WAB 56-104 \\
NERICA 4 & WAB 450-IBP-91-HB & WAB 56-104/CG 14//2*WAB 56-104 \\
NERICA 10 & WAB 450-11-1-1-P41-HB & WAB 56-104/CG 14//2*WAB 56-104 \\
\hline
\end{tabular}

*IBP: Interbreeding population, HB: High input homogeneous bulk, P: Panicle selection. Source: http://www.africarice.org/warda/uplandnerica.asp. 


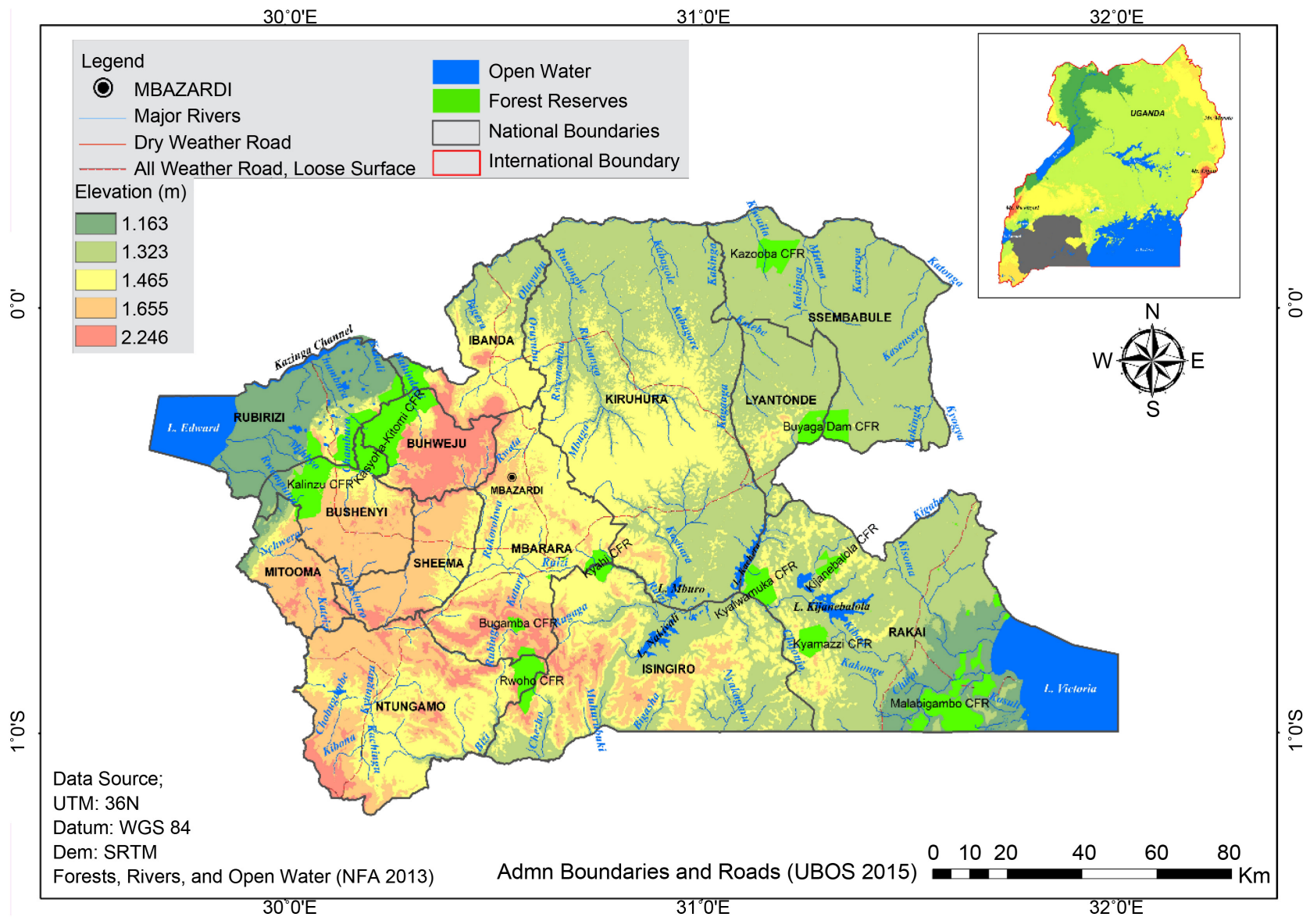

Figure 1. Physical features and location of the south-western agro-ecological zone of Uganda.

The site is 1433 meters above sea level and receives an average annual rainfall of $1373 \mathrm{~mm}$ in bimodal distribution that occurs in March-May and September-December. The least and highest amounts of rainfall occur in January and April, with the average precipitation of 33 and $183 \mathrm{~mm}$, respectively. The temperatures are highest and lowest in February and August with $24.1^{\circ} \mathrm{C}$ and $21.6^{\circ} \mathrm{C}$, respectively [6]. Evapotranspiration of the area $(1300-1450 \mathrm{~mm})$, is lower than most of the surrounding areas that are close to water bodies. The experiment was conducted in the long rain season of 2010 that had an average monthly precipitation was $130 \mathrm{~mm}$ (Figure 2). The experimental area is predominated by ferrallitic soils, which are mainly sandy loams and sandy clay loams with good drainage [7].

\subsection{Experiment Establishment, Data Collection and Analysis}

The experiment was established purely under rain-fed conditions. Dry sowing of NERICA was done in late August in well pulverized soils to capture sufficient rains of September-December. Three NERICA varieties: NERICA 1, NERICA 4, and NERICA 10, were planted in plots of $3 \mathrm{~m} \times 4 \mathrm{~m}$, arranged with three replicates in a Complete Randomized Block Design (CRBD). Planting was done by dibbling at depth, spacing and seed rate of $3 \mathrm{~cm}, 30 \times 12.5 \mathrm{~cm}$, and $60 \mathrm{~kg} \cdot \mathrm{ha}^{-1}$, 


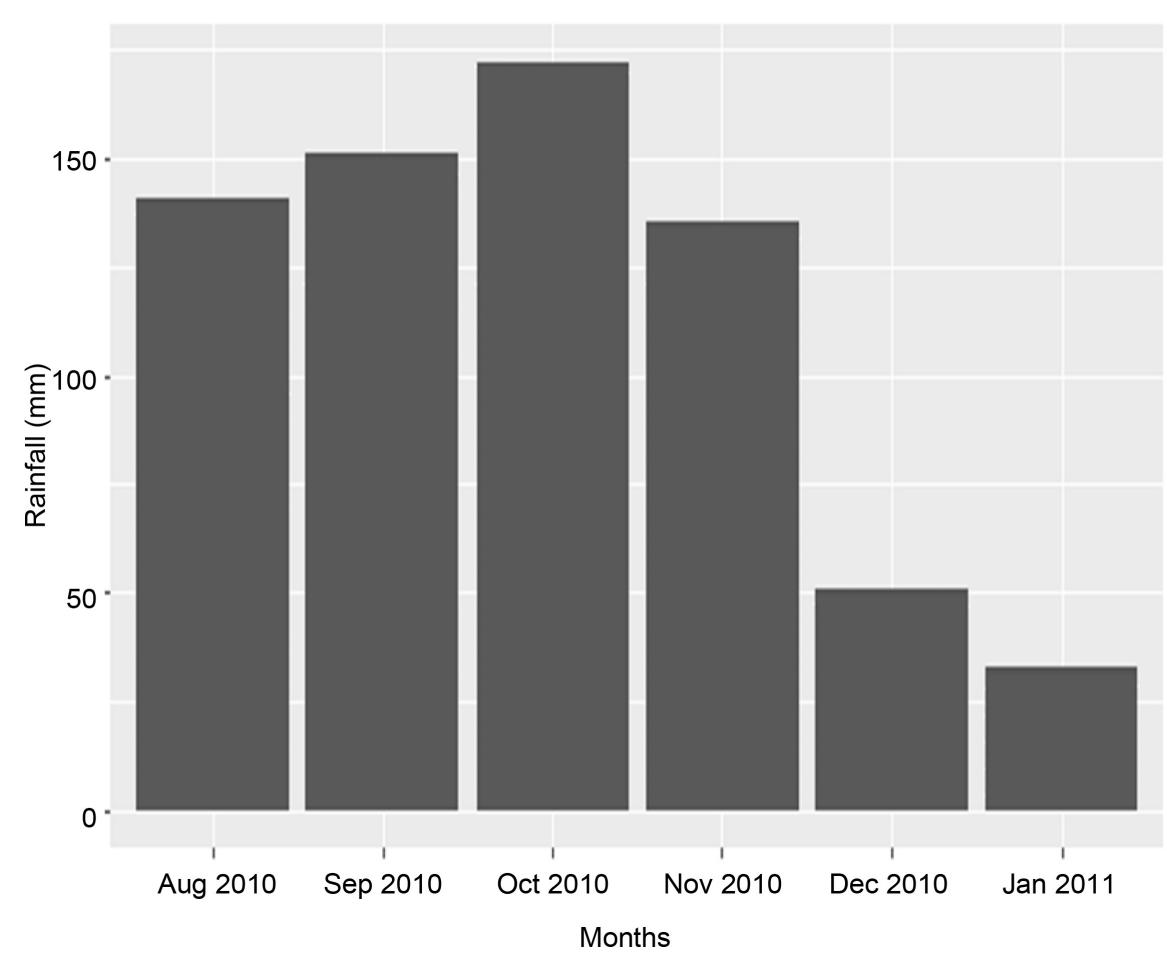

Figure 2. Total monthly rainfall during study period.

respectively. Standard cultural practices for rice production and management were followed during the entire growth period.

The agronomic data collected included plant heights at 4, 6 and 8 weeks after planting (WAP). Further, plant heights were also measured at the time of harvesting. At harvesting, grain yield components were determined by sampling 20 hills from each plot. Grain yields were adjusted to grain moisture content of $14 \%$, and expressed into $\mathrm{kg} \cdot \mathrm{ha}^{-1}$. Data were subjected to analysis of variance (ANOVA). Whenever significant differences were detected ( $\mathrm{p}=0.05$ ), the means were compared using the Tukey's HSD test at $5 \%$ levels of significance.

\section{Results and Discussion}

Plant height for NERICA 10 was significantly shorter $(\mathrm{p}<0.05)$ than that of NERICA 1 and NERICA 4 at all stages of physiological growth (Figure 3). On the other hand, plant height for NERICA 4 was not significantly $(p>0.05)$ different from that of NERICA 1 . The variation in plant heights between NERICA 10 and other tested NERICA varieties was due to inherent differences of the genotypes [7]. This indicated that, there was wider genomic gap expression for plant heights between NERICA 10 and other tested NERICA varieties. This also indicated that, there was narrow genomic gap expression for plant heights between NERICA 1 and NERICA 4 grown under the semi-arid conditions of the SWAEZ.

NERICA 10 exhibited lower lodging potential compared to NERICA 1 and NERICA 4. This was because NERICA 10 had shorter and sturdier stems at the 


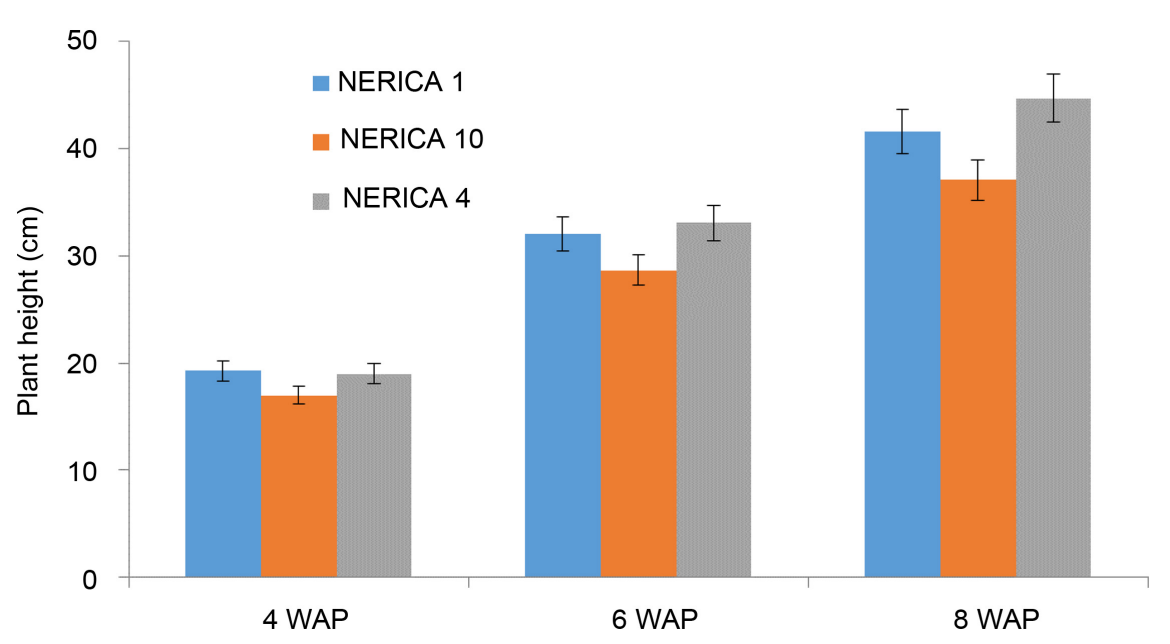

Figure 3. Variation of plant heights of NERICA varieties over time.

lower parts of the plant to support the whole plant and its grains at maturity compared to NERICA 1 and NERICA 4. Nonetheless, NERICA 1 and NERICA 4 could benefit from tall heights to avoid being smothered by weeds, and therefore could be able to capture more sunlight for photosynthesis compared to NERICA 10 under weed-infested fields.

There were no significant differences in number of tillers and grain weights per plant for all the three NERICA varieties (Table 2), indicating a narrow genomic gap expression in terms of tillers per plant among the studied NERICA varieties under the semi-arid conditions of SWAEZ. Narrow physio-genomic expression among some NERICA varieties was also observed in other studies conducted under same environmental conditions [8]. NERICA 1 had significantly lower number of panicles per plant compared to NERICA 4 and NERICA 10. This indicated that there was a distinct genomic gap expression for number of panicles per plant under SWAEZ condition between NERICA 1 and other NERICA varieties that had not expressed significant differences in the number of panicles per plant. On the other hand, NERICA 4 had significantly higher grain yields per plant compared to NERICA 1 and NERICA 10 that had not expressed significant differences in grain yields between them. This indicated that there was wider genomic expression gap in terms of grain weight per plant between NERICA 4 and other tested NERICA varieties. Variations grain weights per plant is due to differences in genetic trains among the NERICA varieties [8].

There were significant differences $(\mathrm{p}<0.05)$ in grain yields among the tested NERICA varieties, with NERICA 4 having the highest grain yields: two-folds of grain yields of NERICA 1 (Figure 4). This indicated that, NERICA 4 was the most superior in terms of grain yields among the three tested NERICA varieties under the semi-arid conditions of the SWAEZ. However, grain yields of NERICA 4 were four-folds lower than that obtained on station located in the humid, central Uganda: Namulonge Crops Resources Research Institute (NACRRI), the breeder for NERICA in Uganda. It was also below the national average of 
Table 2. Variation in number of tillers and panicle characteristics with NERICA varieties.

\begin{tabular}{ccccc}
\hline $\begin{array}{c}\text { NERICA } \\
\text { variety }\end{array}$ & $\begin{array}{c}\text { No. of tillers } \\
\text { per plant }\end{array}$ & $\begin{array}{c}\text { No. panicles per } \\
\text { plant }\end{array}$ & $\begin{array}{c}\text { Grain weight } \\
\text { per panicle (g) }\end{array}$ & $\begin{array}{c}\text { Grain weight } \\
\text { per plant (g) }\end{array}$ \\
\hline NERICA 1 & $8.33^{\mathrm{a}}$ & $3.78^{\mathrm{a}}$ & $1.20^{\mathrm{a}}$ & $3.98^{\mathrm{a}}$ \\
NERICA 4 & $7.37^{\mathrm{a}}$ & $4.67^{\mathrm{b}}$ & $2.54^{\mathrm{b}}$ & $5.00^{\mathrm{a}}$ \\
NERICA 10 & $8.60^{\mathrm{a}}$ & $5.45^{\mathrm{b}}$ & $1.08^{\mathrm{a}}$ & $4.87^{\mathrm{a}}$ \\
\hline
\end{tabular}

a, b ... are DMRT alphabets. Means followed by similar alphabet are not significantly different from one another.

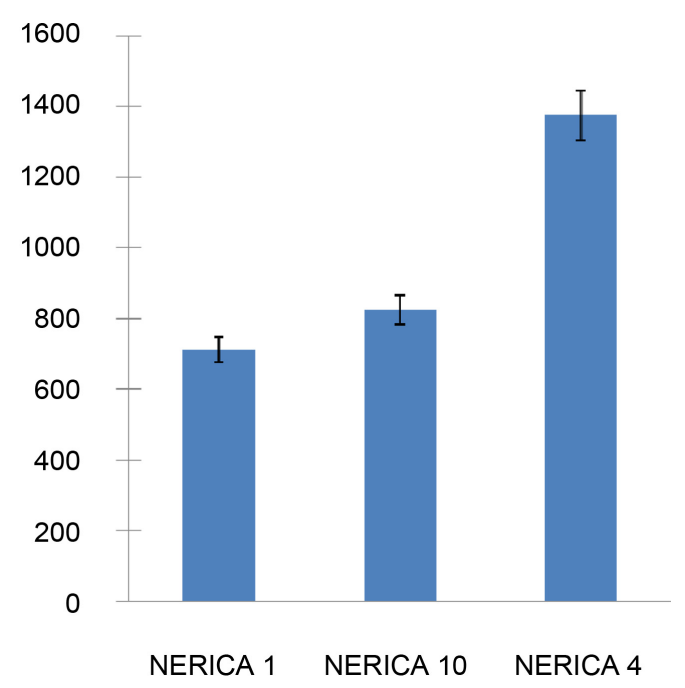

Figure 4. Variation of grain yields with the tested NERICA varieties.

rice productivity estimated at $2.5 \mathrm{t} \cdot \mathrm{ha}^{-1}$. Grain yields for NERICA 4 in the traditional rice producing areas are estimated at $2.0-3.3 \mathrm{t} \cdot \mathrm{ha}^{-1}$ under rain-fed conditions [9]. Hence, areas of the SWAEZ exhibiting typical conditions of semi-arid conditions may not be suitable for upland NERICA production due to its limited and unpredictable rains.

\section{Conclusion}

Experimental trial of upland NERICA on-station at MBAZARDI revealed the following: while upland NERICA 1 and NERICA 4 had taller heights compared to NERICA 10, NERICA 4 had the highest grain yields. This placed NERICA 4 , the most possible top candidate for rice farmers found in more humid parts of the SWAEZ of Uganda. The limited and unpredictable rains in the SWAEZ, make large areas of the SWAEZ less suitable for upland NERICA production, which calls for more breeding for drought tolerance, targeting parts of SWAEZ with pronounced semi-arid conditions.

\section{Conflicts of Interest}

The authors declare no conflicts of interest regarding the publication of this paper. 


\section{References}

[1] Bigirwa, T., Kikafunda, J. and Onega, G. (2005) Experience in NERICA Dissemination in Uganda. Proceedings of the Workshop on NERICA Promotion in East Africa, Juja Nairobi.

[2] MAAIF (2009) Uganda National Rice Development Strategy.

[3] GoU (Government of Uganda) (2016) Uganda Wetlands Atlas, 2, 1-42.

[4] ADB (2014) Increasing Domestic Production, Improving Food Security.

[5] Kaneda, C. (2007) Breeding and Dissemination Efforts of "NERICA" (1) Breeding of Upland Rice. Japanese Journal of Tropical Agriculture, 51, 1-4.

[6] World Weather Channel (2019) World Weather Online. https://www.worldweatheronline.com

[7] Isabirye, M., Mwesige, D., Ssali, H., Magunda, M. and Lwasa, J. (2004) Soil Resource Information and Linkages to Agricultural Production. Uganda Journal of Agricultural Sciences, 9, 215-221.

[8] Fukuta, Y., et al. (2012) Genetic Characterization of Rainfed Upland New Rice for Africa (NERICA) Varieties. Breeding Science, 62, 27-37. https://doi.org/10.1270/jsbbs.62.27

[9] Fujiie, H., Agency, C., Fujiie, M., Kurauchi, N. and Takagaki, M. (2010) Potential of NERICA Production in Uganda. Trop. Agric. Dev., 54, 44-50. 